\title{
Algorithm for Differential Diagnosis of in Vitro and in Vivo Hemolysis in Anticoagulated Blood Specimens
}

Jong-Han Lee ${ }^{1}$, Yoonjung $\mathrm{Kim}^{2}$, Gilsung Yoo', Juwon $\mathrm{Kim}^{1}$, Kap Jun Yoon ${ }^{1}$, and Young $\mathrm{Uh}^{1}$

${ }^{1}$ Department of Laboratory Medicine, Yonsei University Wonju College of Medicine, Wonju; ${ }^{2}$ Department of Laboratory Medicine, Yonsei University College of Medicine, Seoul, Korea

Corresponding author: Young Uh

Department of Laboratory Medicine, Yonsei University Wonju College of Medicine, 20 Ilsan-ro, Wonju 26426, Korea Tel: $+82-33-741-1592$

Fax: +82-33-731-0506

E-mail: u931018@yonsei.ac.kr

pISSN: 2384-2458

elSSN: 2288-7261
Background: Hemolytic specimens contain components that interfere with clinical laboratory results. We evaluated previously published hemolysis indices (HI) and developed an algorithm for differentiating between mechanical hemolysis and immune-mediated hemolysis based on complete blood count (CBC).

Methods: Sixty-three residual EDTA (ethylenediamine tetraacetic acid)-anticoagulated blood specimens were obtained during regular health check-ups, and each specimen was divided into 3 aliquots (A control, B, and C group). Aliquots B and C were mechanically hemolysed by 2 and 5 aspirations, respectively, using a 25-gauge needle before testing; aliquot A was analysed immediately without hemolysis. Additionally, we collected 36 specimens from patients suspected of having immune-mediated hemolysis after thorough reviewing their various laboratory results including direct antiglobulin test. We compared $\mathrm{CBC}$ parameters between the groups $(\mathrm{A}, \mathrm{B}, \mathrm{C}, \mathrm{D}[\mathrm{B}+\mathrm{C}]$, and $\mathrm{E}$ [immune-mediated hemolysis group]).

Results: Our HI scoring system using the sum of red blood cell ghosts, measured hemoglobin-calculated hemoglobin, mean corpuscular hemoglobin concentrationcorpuscular hemoglobin concentration mean, and mean platelet volume rather than mean corpuscular hemoglobin, effectively identified mechanical hemolysis; the results were similar to those of previous studies. Furthermore, the HI score using the sum of mean corpuscular volume, red cell distribution width, hemoglobin distribution width, polymorphonuclear $\%$, and neutrophil \% differentiated mechanical hemolysis from immune-mediated hemolysis (cut-off, 9; sensitivity, 91.7\%; specificity, 92.9\%; area under the receiver operating characteristic curve, 0.965 [95\% confidence interval, 0.924-0.988]).

Conclusions: The newly developed algorithm may provide effective screening for detecting hemolysis and differential diagnosis of mechanical hemolysis and immune-mediated hemolysis based on CBC results.

(J Lab Med Qual Assur 2017;39:132-140)

Key Words: Hemolysis, Mechanical, Immune-mediated, Red blood cell, Complete blood count

Received April 14, 2017, Revision received August 18, 2017, Accepted August 21, 2017

\section{서론}

적혈구(red blood cell) 용혈은 임상검사실에서 황달 검체 및 고지질 검체와 더불어 가장 흔한 검사오류를 유발할 수 있다 〔1]. 적혈구 용혈 검체는 비용혈 검체에 비해 채혈 용기 내의 헤모글로빈 농도가 높아져 흡광도 원리를 이용하는 여러 가지 검사장비에서 간섭을 유발할 수 있다. 예를 들면, 젖산탈수소 효소(lactate dehydrogenase, $\mathrm{LDH}$ ), 아스파르테이트아미노 전달효소(aspartate aminotransferase, AST), 알라닌아미노 전달효소(alanine aminotransaminase, ALT), 칼륨, 무기인, 칼슘 등은 증가하고, 포도당, 나트륨 등은 감소시키는 것으로 알려져 있다[2].

용혈 검체를 올바르게 선별하는 경우 용혈에 의해 결과값이 증가하거나 감소할 가능성이 있는 검사항목과 그 수준을 보고 


\section{Journal of LABORATORY MEDICINE and QUALITY ASSURANCE}

Jong-Han Lee et al $\bullet$ Differentiating Mechanical and Immune Hemolysis

할 수 있고, 불필요한 재검사 등을 줄이게 됨으로써 검사비용 의 감소와 보고시간의 단축효과를 가져올 수 있다. 또한 채혈 과정이나 채혈용기 혼합 등의 물리적 원인에 의한 적혈구 용혈 과 면역성 원인에 의한 용혈의 구별까지 가능하다면 용혈질환 의 조기선별진단에 도움이 되리라 판단된다.

진단검사의 결과 오류는 검사 전 단계, 검사과정 단계 및 검 사 후 단계로 구분된다. 검사과정 및 검사 후의 오류는 검사장 비와 시약의 고도화와 개선으로 감소하고 있으며, 검사 전 오 류를 줄이려는 노력이 더욱 요구되고 있다. 검사 전 오류의 방 지책으로 delta check, 검체 정보 정도관리, 검사실 정보화 (laboratory information system) 및 환자인식시스템의 구 축 등의 여러 방법이 이용되고 있다. 그러나 검사결과에 영향 을 미치는 적혈구 용혈은 환자 요인, 채혈자, 채혈 용기 등 여 러 가지 원인에 의해 발생하고 있으므로 이에 대한 조기선별 및 대처가 중요하다. 실제 임상검사실에서는 용혈 검체에 대 한 판단과 그 해석도 또한 중요한데, Laposata와 Dighe [3] 의 보고에 의하면 검사실 전문가가 부재한 경우에 특정 질환에 서 $75 \%$ 의 사례에서 해석 오류와 연관이 있었다는 보고도 있 는 만큼 임상검사실에서의 정확한 해석은 필수적이라 하겠다. 검사실 내 자동화 검사장비는 일반적으로 분광광도계로 혈청 내의 용혈, 빌리루빈, 지질(hemolysis, icterus, lipemia, HIL) 농도를 측정하여 HIL 값과 index를 보고하며, 검사종목별로 $10 \%$ 이상의 증감을 기준으로 HIL index의 threshold (alert) 가 설정되어 있다[4,5].

이에 반해 항응고제를 사용하여 전혈로 검사하는 온혈구검 사(complete blood cell count)는 검체를 원심분리하지 않으므 로 검체 내의 용혈을 확인하기가 어렵다. 이번 연구에서는 온 혈구검사에서 물리적 원인으로 인한 적혈구 용혈의 존재를 선 별할 수 있는 scoring system을 구축하여 기존 검체 내 용혈검 출시스템〔6]과 비교하고 동시에 물리적인 원인의 적혈구 용혈 군과 면역성 적혈구 용혈을 감별할 수 있는 알고리즘을 개발하 고자 하였다.

\section{재료 및 방법}

\section{1. 온혈구검사에서 물리적 요인으로 인한 적혈구 용혈의 선 별방법 개발과 평가}

2015년 4월에서 5월까지 건강검진을 위해 내원한 검진자 를 대상으로 potassium ethylenediamine tetraacetic acid (EDTA) 채혈용기(BD Vacutainer K2 EDTA $5.4 \mathrm{mg}$; Becton Dickinson, Franklin Lakes, NJ, USA)에 채혈하 여 검사한 후 남은 잔여 검체를 대상으로 하였으며, Yoo 등[6]
의 보고에 의한 hemolytic index (HI)와 원심분리 후 혈장 측 정 $\mathrm{LDH}$ 가 참고범위를 벗어난 경우는 분석대상에서 제외하 였다. 최종 63 명의 검체를 확보한 후, 각 검체를 3 개로 분주하 였다. 첫 분주 검체는 대조군(A군)으로 선정하여 온혈구검사 를 시행하였고, 두 번째와 세 번째 분주 검체는 각각 25-gauge 바늘 주사기를 이용하여 2회(B군)와 5 회(C군) 흡인과 유출 을 반복하여 인위적인 용혈을 만든 후에 온혈구검사를 시행 하였다. 온혈구검사는 Advia 2120i (Siemens Healthcare Diagnostics, Sacramento, CA, USA) CBC/Diff mode를 이용하였다. $\mathrm{LDH}$ 는 분주한 검체를 원심분리 후 혈장을 대 상으로 Cobas 8000 자동화학분석장비(Roche Diagnostics, Bazel, Switzerland)로 측정하였다. HI는 평균적혈구헤모 글로빈농도(mean corpuscular hemoglobin concentration, $\mathrm{MCHC}$ ), 적혈구 ghosts, measured hemoglobin-calculated hemoglobin ( $\mathrm{mHb}-\mathrm{cHb}$ )와 MCHC-corpuscular hemoglobin concentration mean $(\mathrm{CHCM})$ 수준의 점수의 합으로 그 범위 는 다음과 같다[6]. $\mathrm{MCHC}(\mathrm{g} / \mathrm{dL})$ : 점수 $0<34.0,34.0 \leq$ 점 수 $1<36.3,36.3 \leq$ 점수 $2<38.5$, 그리고 점수 $3 \geq 38.5$; 적 혈구 ghosts $\left(10^{6} / \mu \mathrm{L}\right)$ : 점수 $0<0.02,0.02 \leq$ 점수 $1<0.03$, $0.03 \leq$ 점수 $2<0.04$, 점수 $3 \geq 0.04 ; \mathrm{mHb}-\mathrm{cHb}(\mathrm{g} / \mathrm{dL})$ : 점 수 $0<0.13,0.13 \leq$ 점수 $1<0.39,0.39 \leq$ 점수 $2<1.31$, 그 리고 점수 $3 \geq 1.31$; $\mathrm{MCHC}-\mathrm{CHCM}(\mathrm{g} / \mathrm{dL})$ : 점수 $0<0.26$; $0.26 \leq$ 점수 $1<0.96,0.96 \leq$ 점수 $2<3.35$, 그리고 점수 3 $\geq 3.35$ 로 선정하였다(Table 1).

원 검체와 인위적 용혈을 유발시킨 2 개의 분주 검체에서의 온혈구검사를 수행한 후 정상군(A군), 2회 물리적 용혈군(B 군), 5 회 물리적 용혈군(C군), $\mathrm{B}$ 군과 $\mathrm{C}$ 군의 합( $\mathrm{D}$ 군)의 각각 의 군을 대상으로 그룹 간의 차이를 비교 분석하여 용혈에 의 해 통계적으로 유의한 차이가 있는 온혈구검사의 변수들을 선 정하였다. 물리적 요인으로 인한 검체 내 용혈 감별 알고리즘 에 해당하는 혈액검사 변수(hematologic parameter)를 선 정 후 용혈 감별 알고리즘의 효율성을 평가하고자 receiver operating characteristic $(\mathrm{ROC})$ 곡선을 산출하고 기존 알고 리즘과 비교하였다[6].

\section{2. 물리적 요인으로 인한 적혈구 용혈과 면역과 관련된 적혈 구 용혈의 비교}

2015년 5월부터 12월까지 검사결과를 통하여 면역과 관 련된 적혈구 용혈이 의심될 때는 온혈구계산 후 잔여 검체로 $\mathrm{LDH}, \mathrm{AST}, \mathrm{ALT}, \mathrm{HI}$, 합토글로빈, 빌리루빈(직접, 간접), 쿰 즈검사(직접, 간접)와 $\mathrm{C}$ 반응단백 결과를 검사한 후 말초혈액 펴바른표본을 제작하여 판독하여 면역성 적혈구 용혈 36 건 $(\mathrm{E}$ 
Journal of LABORATORY MEDICINE and QUALITY ASSURANCE

Jong-Han Lee et al • Differentiating Mechanical and Immune Hemolysis

Table 1. Range of hemolysis score calculation for identifying mechanical hemolysis

\begin{tabular}{|c|c|c|c|c|c|}
\hline Score ${ }^{\star}$ & $\mathrm{MCHC}(\mathrm{g} / \mathrm{dL})$ & MPV (fL) & $\mathrm{RBC}$ ghost $\left(10^{6}\right.$ cells $\left./ \mu \mathrm{L}\right)$ & $\mathrm{mHb}-\mathrm{cHb}(\mathrm{g} / \mathrm{dL})$ & MCHC-CHCM (g/dL) \\
\hline 0 & $<34$ & $<7.3$ & $<0.02$ & $<0.13$ & $<0.26$ \\
\hline 1 & $34 \leq<36.3$ & $7.3 \leq<7.8$ & $0.02 \leq<0.03$ & $0.13 \leq<0.39$ & $0.26 \leq<0.96$ \\
\hline 3 & $\geq 38.5$ & $\geq 8.5$ & $\geq 0.04$ & $\geq 1.31$ & $\geq 3.35$ \\
\hline
\end{tabular}

Abbreviations: MCHC, mean corpuscular hemoglobin concentration; MPV, mean platelet volume; RBC, red blood cell; mHb, measured hemoglobin; cHb, calculated hemoglobin; CHCM, corpuscular hemoglobin concentration mean.

${ }^{*}$ Example of hemolysis score calculation: If MCHC $35 \mathrm{~g} / \mathrm{dL}, \mathrm{MPV} 7.9 \mathrm{fL}, \mathrm{RBC}$ ghost $0.03 \times 10^{6}$ cells/ $\mu \mathrm{L}, \mathrm{mHb}-\mathrm{cHb} 0.5 \mathrm{~g} / \mathrm{dL}$, and MCHC$\mathrm{CHCM} 1 \mathrm{~g} / \mathrm{dL}$, new algorithm is $\mathrm{MPV}(2)+\mathrm{RBC}$ ghost $(2)+\mathrm{mHb}-\mathrm{cHb}(2)+\mathrm{MCHC}-\mathrm{CHCM}(2)=8$ and old algorithm is $\mathrm{MCHC}(1)+\mathrm{RBC}$ $\operatorname{ghost}(2)+\mathrm{mHb}-\mathrm{cHb}(2)+\mathrm{MCHC}-\mathrm{CHCM}(2)=7$.

군)을 확인하였다.

물리적 요인으로 인한 적혈구 용혈군(D군)과 면역성 적혈 구 용혈군(E군) 간의 통계적으로 유의한 차이가 있는 온혈구 검사의 변수들을 선정하였다. 변수 선정순서는 다음과 같다. (1) 변수종목 값의 범위가 D군과 $\mathrm{E}$ 군의 $95 \%$ 신뢰구간을 기 준으로 겹치지 않는 종목을 선정, (2) 통계적으로 유의한 차이 를 보이는 종목 중 면역성 원인으로 인한 용혈군에서 증가하는 종목을 선정, (3) 온혈구검사 지표 중 정량 값으로 보고되는 항목을 선정, (4) 망상적혈구 관련 지표는 제외하였으며, 관련 지표는 Advia 2120i (Siemens Healthcare Diagnostics)에서 제공하는 매뉴얼을 참고하였다[7]. 용혈 감별 알고리즘에 해 당하는 혈액검사 변수를 선정 후 면역성 원인의 적혈구 용혈을 물리적인 원인으로 인한 적혈구 용혈과 감별하는 알고리즘을 개발하고자 하였다.

\section{3. 통계분석}

모든 변수들은 Kolmogorov-Smirnov test로 정규성 검증 을 시행하였으며, A, B, C, D, E군 간의 비교를 위해 MannWhitney $U$ 분석을 통하여 개별 그룹 간 차이를 확인하였다. 통계적으로 유의한 차이를 보이는 지표들을 포함하는 새로운 알고리즘이 기존 알고리즘과 비교하여 물리적 용혈을 정상군 과 감별하는 능력을 재확인하고, 물리적 용혈군과 면역성 용 혈군 감별능력을 비교하고자 ROC 커브분석을 시행하였다. 통 계적 유의성은 $P$ 값이 0.05 미만인 경우로 하였고, 모든 통계분 석은 IBM SPSS Statistics ver. 23.0 (IBM Corp., Armonk, NY, USA)과 MedCalc ver. 17.2 (Medcalc, Ostend, Belgium)을 이용하여 분석하였다.

\section{결과}

\section{1. 온혈구검사에서 물리적 요인으로 인한 용혈의 선별}

평균혈소판용적 (mean platelet volume, $\mathrm{MPV}$ ), 적혈구 ghosts, $\mathrm{mHb}-\mathrm{cHb}, \mathrm{MCHC}-\mathrm{CHCM}$ 의 4 가지 지표가 대조군 $\mathrm{A}$ 군과 물리적 용혈군 $\mathrm{D}$ 군 간 통계적으로 유의한 차이를 보 여주었다. 물리적인 용혈군 $\mathrm{D}$ 군에서 정상대조군보다 $\mathrm{MPV}$, $\mathrm{mHb}-\mathrm{cHb}$ 와 $\mathrm{MCHC}-\mathrm{CHCM}$ 의 값은 더 높았으며, 적혈구 ghosts가 더 많았다(Table 2). 이를 토대로 기존 Yoo 등[6]이 보고한 $\mathrm{HI}$ 점수에서 $\mathrm{MCHC}$ 대신 이번 연구에서 유의한 지표 인 MPV 값을 포함하였을 때의 ROC curve 분석결과를 비교 해보았다. MPV는 점수 $0<7.3 \mathrm{fL}, 7.3 \leq$ 점수 $1<7.8,7.8$ $\leq$ 점수 $2<8.5$, 점수 $3 \geq 8.5$ 로 계산하였다(Table 1). 용혈을 감별하는 진단 유용성은 동등한 수준이었다 $(P=0.271)$. 새로 운 지표를 적용하여 경계치(cut-off value)를 3으로 정한 경우 의 곡선하면적(area under the curve, AUC)은 0.77로 물리 적 용혈을 선별해내는 민감도는 $53.2 \%$ (95\% 신뢰구간, 44.162.1), 특이도는 88.9\% (95\% 신뢰구간, 78.4-95.4)였다. 기존 의 $\mathrm{YoO}$ 등[6]의 보고로는 경계치를 2로 정하는 경우의 $\mathrm{AUC}$ 는 0.73 로 민감도 $43.7 \%$ (95\% 신뢰구간, 34.8-52.8), 특이도 90.5\% (95\% 신뢰구간, 80.4-96.4)였다(Fig. 1).

\section{2. 온혈구검사에서 물리적 요인의 용혈과 면역성 원인의 용 혈의 감별}

면역성 원인의 용혈의 경우에 물리적 원인에 의한 용혈과 비교하여 측정항목의 다수가 차이를 나타내었다. 즉 면역성 원인의 용혈( $\mathrm{E}$ 군)은 물리적 원인에 의한 용혈군(D군)에 비 해 평균적혈구용적 (mean corpuscular volume, $\mathrm{MCV}$ ), 평 균적혈구혈색소량(mean corpuscular hemoglobin), 적혈 구크기분포폭(red cell distribution width, RDW), 혈색소 분포폭(hemoglobin distribution width, HDW), 혈색소농 
Journal of LABORATORY MEDICINE and QUALITY ASSURANCE

Jong-Han Lee et al • Differentiating Mechanical and Immune Hemolysis

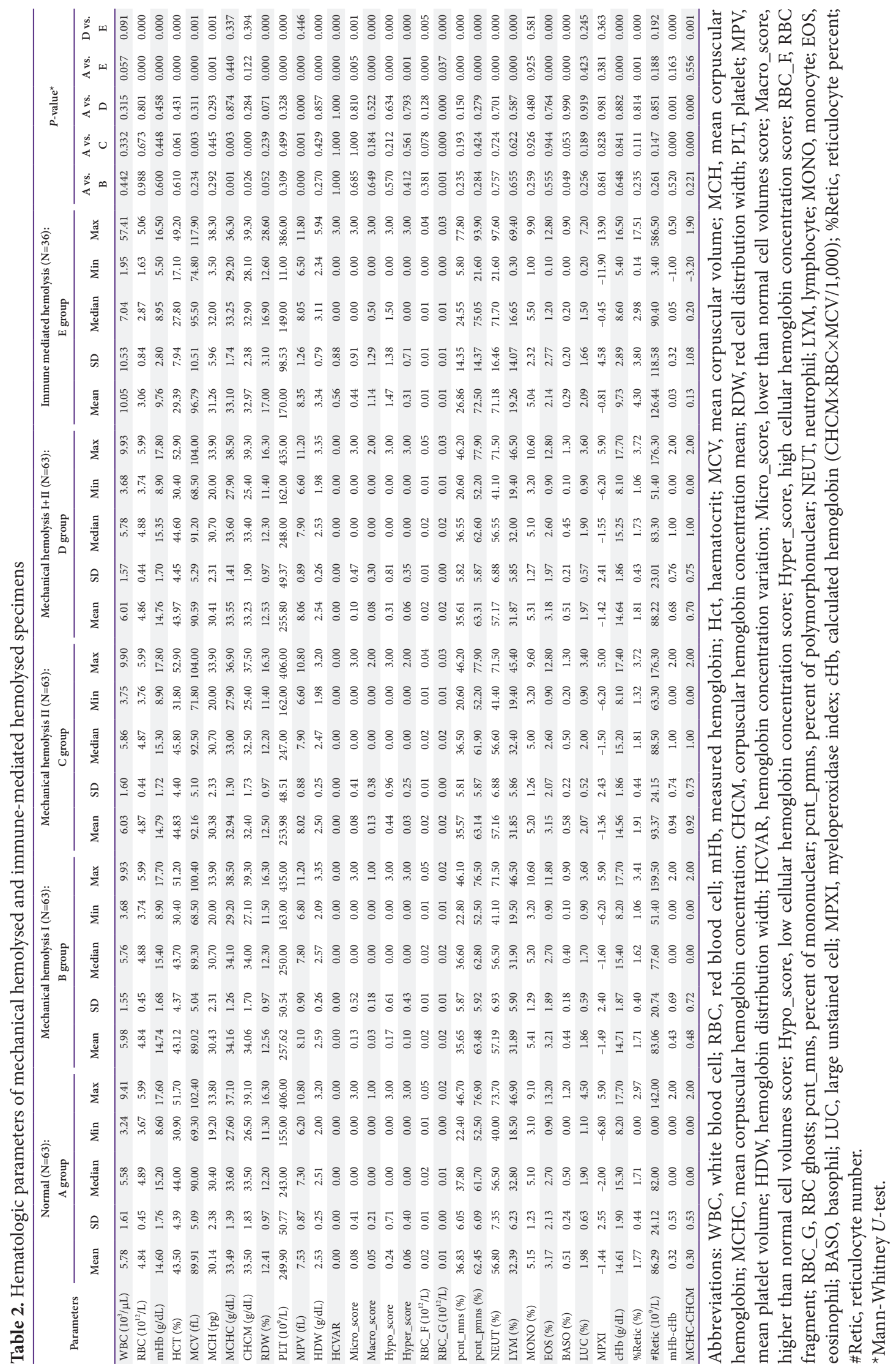




\section{Journal of LABORATORY MEDICINE and QUALITY ASSURANCE}

Jong-Han Lee et al $\bullet$ Differentiating Mechanical and Immune Hemolysis

도변이(hemoglobin concentration variation), low cellular hemoglobin concentration (Hypo_score), higher than normal cell volumes (Macro_score), polymorphonuclear\% (PMN\%), neutrophil\%, reticulocyte\%는 높았으며, 적혈구, $\mathrm{mHb}$, 적혈구용적률(hematocrit), 혈소판 수, 적혈구 ghosts, mononuclear \%, lymphocyte \%, basophil\%, cHb, $\mathrm{mHb}^{-}$

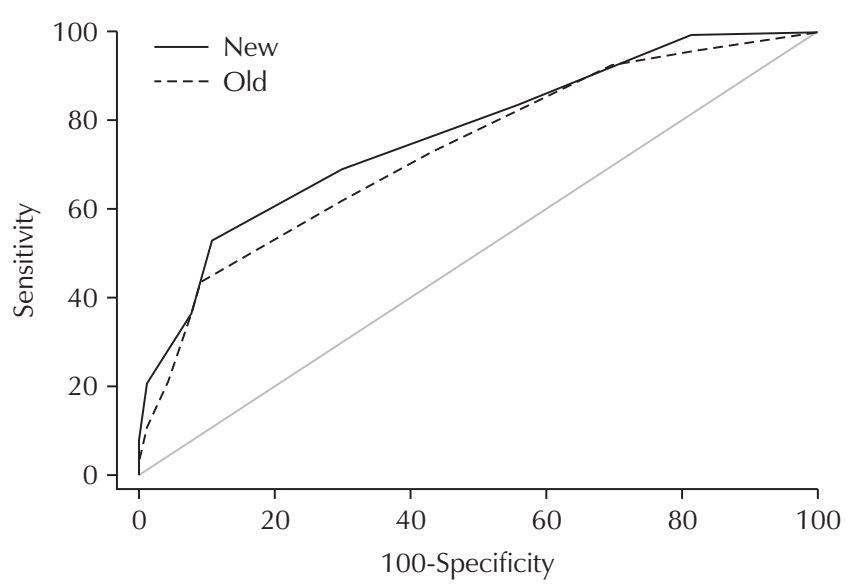

Fig. 1. Comparison of receiver operating characteristic curves between new and old parameters for diagnosis of mechanical RBC hemolysis. New: sum of mean platelet volume score, RBC ghost score, mHb-cHb score, and MCHC-CHCM score (cut-off, 3; AUC, 0.77; sensitivity, 53.2\% [95\% CI, 44.1-62.1]; specificity, 88.9\% [95\% CI, 78.4-95.4]). Old: sum of MCHC score, RBC ghost score, $\mathrm{mHb}-\mathrm{cHb}$ score, and MCHCCHCM score (cut-off, 2; AUC, 0.73; sensitivity, 43.7\% [95\% CI, 34.8-52.8]; specificity, 90.5\% [95\% CI, 80.4-96.4]). Abbreviations: $\mathrm{RBC}$, red blood cell; $\mathrm{mHb}$, measured hemoglobin; cHb, calculated hemoglobin; MCHC, mean corpuscular hemoglobin concentration; CHCM, corpuscular hemoglobin concentration mean; AUC, area under the curve; $\mathrm{CI}$, confidence interval.
cHb, MCHC-CHCM의 수치는 더 낮았다(Table 2). 면역성 용혈의 감별을 위한 알고리즘 구축을 위하여 이번 연구에서는 연구방법 부분에서 언급한 지표선정기준에 의거하여 최종적 으로 $\mathrm{MCV}, \mathrm{RDW}, \mathrm{HDW}, \mathrm{PMN} \%$, neutrophil\%의 다섯 종 목을 중요 지표로 선정 후 그 점수의 합을 추출하여 면역성 원 인의 적혈구 용혈과 물리적 원인의 적혈구 용혈을 구별하는 선 별식을 개발하였다. 종목별 점수 선정을 위한 종목별 참고범위 는 통상적인 혈액검사 참고범위와 $\mathrm{ADVIA}$ 제공 매뉴얼[7]의 예상 값의 하한과 상한을 참고하여 하한 미만(0점), 하한 이상 부터 중간값 미만(1점), 중간값 이상부터 상한값 미만(2점), 상한값 이상(3점)으로 산정하여 분석하였다. 알고리즘을 위한 5 종목의 점수범위는 다음과 같다.

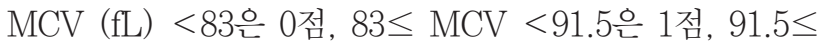
$\mathrm{MCV}<100$ 은 2점, $\mathrm{MCV} \geq 100$ 은 3점, $\mathrm{RDW}(\%)<10$ 은 0 점, $10 \leq \mathrm{RDW}<11.5$ 은 1점, $11.5 \leq \mathrm{RDW}<13$ 은 2점, $\mathrm{RDW}$ $\geq 13$ 은 3점, $\mathrm{HDW}(\%)<1.9$ 은 0점, $1.9 \leq \mathrm{HDW}<2.5$ 은 1 점, $2.5 \leq \mathrm{HDW}<3$ 은 2점, $\mathrm{HDW} \geq 3$ 은 3점 $\mathrm{PMN}(\%)<42$ 은 0점, $42 \leq \mathrm{PMN}(\%)<62$ 은 1점, $62 \leq \mathrm{PMN}(\%)<82$ 은 2점, $\mathrm{PMN}(\%) \geq 82$ 은 3점, neutrophil $(\%)<35 \%$ 은 0점, $35 \leq$ neutrophil $(\%)<55$ 은 1점, $55 \leq$ neutrophil $(\%)<75$ 은 2점, neutrophil $(\%) \geq 75$ 은 3점으로 정하였다. 선별식으 로부터 물리적 원인으로 인한 적혈구 용혈과 면역성 원인으로 인한 적혈구 용혈을 감별하기 위한 점수의 경계치를 산정하기 위하여 점수의 분포를 각 군 간 산출하였다(Table 3). 경계치 점수가 9점에서 10점부터는 면역성 원인의 적혈구 용혈을 의 심할 수 있었다. 이를 토대로 이러한 알고리즘의 효율성을 판 단하기 위하여 $\mathrm{ROC}$ 커브분석을 시행한 결과, 경계치를 9 로 설정했을 때 물리적인 원인에 의한 적혈구 용혈군과 면역성 원 인의 적혈구 용혈을 감별하는 능력은 진단민감도 $91.7 \%$, 진단 특이도 $92.9 \%$, AUC 0.965 (95\% 신뢰구간, 0.924-0.988)이 었으며, 정상 대조군과 물리적 원인으로 인한 적혈구 용혈이

Table 3. Comparison of total score between mechanical hemolysis and immune-mediated hemolysis

\begin{tabular}{|c|c|c|c|c|c|c|c|c|c|c|c|c|c|c|c|c|c|}
\hline \multirow{2}{*}{ Variable } & \multicolumn{17}{|c|}{ Score sum of 5 selected hematologic parameters ${ }^{*}$} \\
\hline & 0 & 1 & 2 & 3 & 4 & 5 & 6 & 7 & 8 & 9 & 10 & 11 & 12 & 13 & 14 & 15 & 16 \\
\hline Non-hemolysis $(\mathrm{N}=63)$ & & & & & & & 2 & 18 & 21 & 19 & 3 & & & & & & \\
\hline Mechanical RBC hemolysis II (N=63) & & & & & & & & 17 & 16 & 25 & 5 & & & & & & \\
\hline Mechanical RBC hemolysis I+II $(\mathrm{N}=126)$ & & & & & & & 4 & 30 & 37 & 46 & 8 & 1 & & & & & \\
\hline
\end{tabular}

Abbreviation: RBC, red blood cell.

${ }^{*}$ Score sum of five parameters: mean corpuscular volume $(\mathrm{fL})$, red cell distribution width (\%), hemoglobin distribution width (g/dL), polymorphonuclear\% (\%), and neutrophil (\%). 

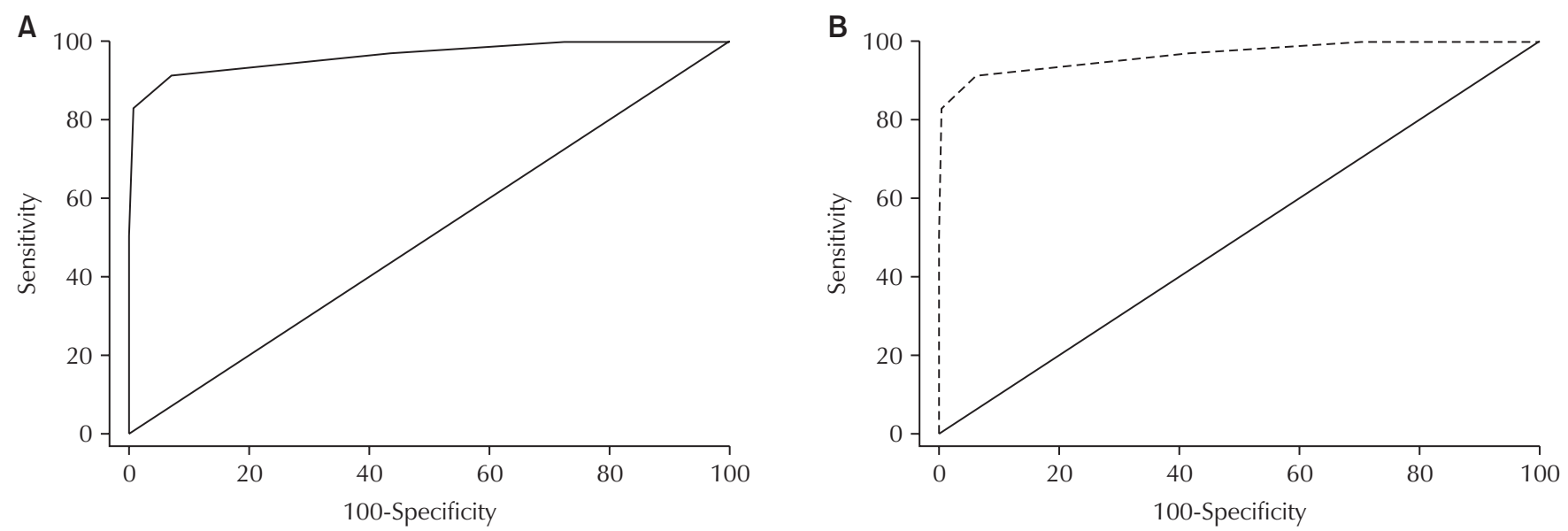

Fig. 2. Receiver operating characteristic curve analysis of new algorithm for differentiating mechanical hemolysis and immune-mediated hemolysis (A) Mechanical hemolysis group vs. immune-mediated hemolysis group. (B) Normal control group + mechanical hemolysis group vs. immune-mediated hemolysis group. (A) Efficiency of differentiating between mechanical hemolysis and immune-mediated hemolysis (cut-off, 9; sensitivity, 91.7\%; specificity, 92.9\%; AUC, 0.965 [95\% CI, 0.924-0.988]). (B) Efficiency of differentiating between sum of normal control and mechanical RBC hemolysis and immune-mediated RBC hemolysis (cut-off, 9; sensitivity, 91.7\%; specificity, 93.7\%; AUC, 0.968 [95\% CI, 0.935-0.987]). Abbreviations: AUC, area under the curve; $\mathrm{CI}$, confidence interval; RBC, red blood cell.

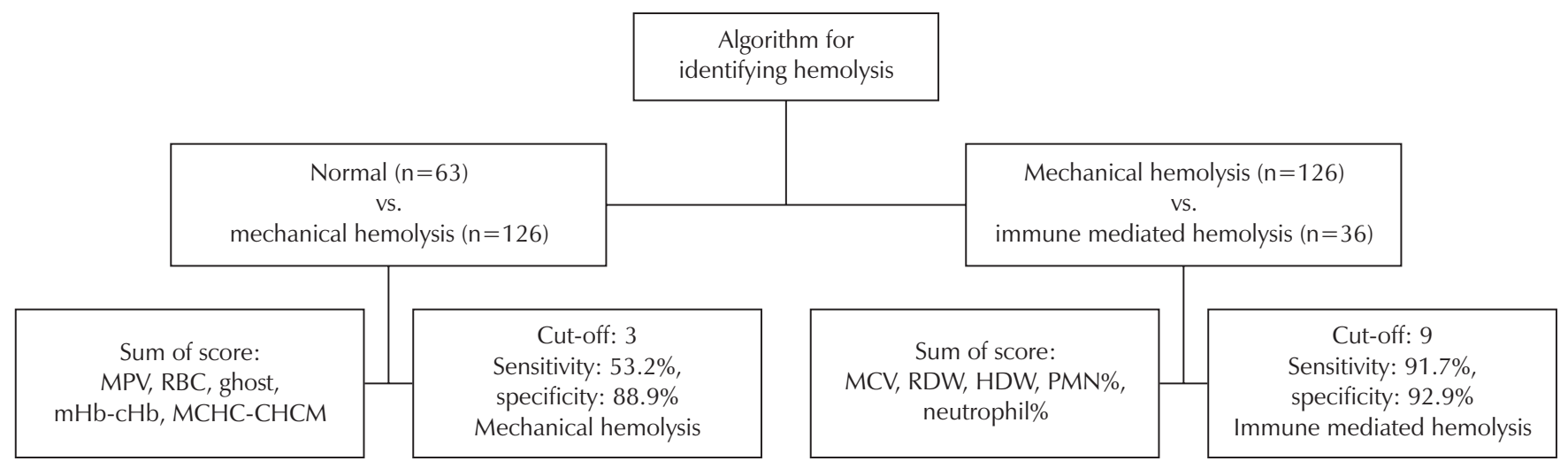

Fig. 3. Flowchart of algorithm for identifying hemolysis. Abbreviations: MPV, mean platelet volume; RBC, red blood cell; $\mathrm{mHb}$, measured hemoglobin; $\mathrm{cHb}$, calculated hemoglobin $(\mathrm{CHCM} \times \mathrm{RBC} \times \mathrm{MCV} / 1,000)$; $\mathrm{MCV}$, mean corpuscular volume; $\mathrm{MCHC}$, mean corpuscular hemoglobin concentration; $\mathrm{CHCM}$, corpuscular hemoglobin concentration mean; RDW, red cell distribution width; HDW, hemoglobin distribution width; PMN, percent of polymorphonuclear.

혼재된 군과 면역성 원인의 적혈구 용혈을 구별하는 능력은 진 단민감도 $91.7 \%$, 진단특이도 $93.7 \%$, AUC 0.968 (95\% 신뢰 구간, 0.935-0.987)로 높은 수준이었다(Fig. 2). 도출된 용혈 감별 알고리즘을 Fig. 3과 같이 정리하였다.

\section{고찰}

이번 연구는 임상 검체 취급 시 여러 가지 검사에 영향을 줄
수 있는 적혈구 용혈을 그 원인 별로 구별해내는 알고리즘을 구축하여 실제 임상에서 적용이 가능한 모델을 만들어 보려 는 목적으로 시행되었다. 적혈구 용혈은 혈청 내 헤모글로빈 의 농도를 증가시켜 측정장비의 흡광도를 높여 여러 가지 검사 결과를 거짓으로 증가시키는 오류를 범할 수 있기 때문에[8] 검사실에서 일차적으로 확인하고 검사를 수행해야 한다. 일 반적으로 적혈구의 용혈은 그 원인이 적혈구 자체에 있는 경 우(intrinsic causes)와 적혈구 외의 원인(extrinsic causes) 


\section{Journal of LABORATORY MEDICINE and QUALITY ASSURANCE}

Jong-Han Lee et al $\bullet$ Differentiating Mechanical and Immune Hemolysis

에 의한 용혈로 구별될 수 있으며, 유전성과 후천성, 용혈이 유발된 장소에 의해 혈관 내(intravascular) 용혈과 혈관 외 (extravascular) 용혈 등으로 구별된다[9]. 임상검사실에서는 흔히 채혈과정이나 채혈 이후 혈액용기에 담는 과정 및 채혈용 기와 항응고제를 혼합하는 과정에서 일어나는 물리적 원인에 의한 적혈구 용혈을 고려할 수 있다. 이 경우 적혈구표면에 가 해지는 압력이 과도하여 용혈이 유발되는 것으로, 주사기 바 늘이 너무 작은 경우, 채혈 후 용기를 과도하게 흔들어 혼합하 는 경우, 알코올이 마르기 전에 채혈을 하는 경우 등에 의해 주 로 발생하는 것으로 알려져 있다[2]. Laessig 등[10]에 의하면 $1 \%$ 용혈로 인하여 $\mathrm{LDH}$ 가 가장 크게 영향을 받으며 이외에 도 칼륨, 크레아틴인산활성효소, AST, ALT와 철 등도 영향받 는 것으로 보고하였다. Lippi 등[1]에 의하면 유리 헤모글로빈 이 $2 \mathrm{~g} / \mathrm{L}$ 이상인 경우 모든 검사에서 영향을 줄 수 있으며 0.6$2 \mathrm{~g} / \mathrm{L}$ 라면 심장표지자, 베타 사람융모성 생식샘자극호르몬, 포도당, 크레아틴인산활성효소, 프로트롬빈시간, 활성화부분 트롬보플라스틴시간, D-이합체에 영향을 주며, 0.3-0.6 g/L이 면 칼륨, 아미노트랜스페라제, $\mathrm{LDH}$ 등에 영향을 줄 수 있다고 보고하였다. 한편, 온혈구검사를 위한 EDTA 전혈 검체의 경 우는 원심분리를 진행하지 않으므로 육안 구별이 어렵다. 이에 본 연구에서는 Yoo 등〔6]에 의한 기존 방법으로 구별하는 방 법을 적용해 본 결과 기존 지표 외에 $\mathrm{MCHC}$ 대신 $\mathrm{MPV}$ 가 유 용한 것으로 분석되었고, $\mathrm{MCHC}$ 대신 $\mathrm{MPV}$ 지표를 추가하여 분석한 결과 기존 알고리즘과 비슷한 수준으로 용혈 검체를 선 별할 수 있었다. MPV는 혈소판 수와 더불어 손상된 혈액세포 와 세포질 절편의 간섭으로 거짓 증가되고[11], 용혈 검체에서 유의한 증가를 나타낸다고 보고되었다[12]. 또한 MPV는 비특 이적으로 염증질환, 각종 암질환, 고혈압, 당뇨 등에서 증가하 는 것으로 알려져 있다[13]. 따라서 $\mathrm{MCHC}$ 대신 MPV가 유의 한 차이를 보여준 것이 실험 대상군의 임상 차이로부터 기인할 가능성이 있다고 판단된다.

이번 연구는 기존 연구와의 비교뿐 아니라 새롭게 물리적인 원인의 적혈구 용혈과 면역성 원인의 적혈구 용혈을 감별할 수 있는 지표도 개발하여 유용성을 평가하였다. 반복적인 주사기 흡인과 유출을 통해 만들어진 물리적 원인의 적혈구 용혈군과 임상 잔여 검체 중 면역성 용혈이 강력히 의심되는 검체들의 온혈구검사 지표를 비교분석하여 통계적으로 유의한 차이를 보이는 지표를 선정한 뒤 이들 지표의 점수의 총합을 이용하 여 면역성 적혈구 용혈과 물리적 원인의 적혈구 용혈을 구별해 보고자 한 것이다. 그러나 본 연구는 다음과 같은 몇 가지 제한 점을 갖고 있다. 첫째, 물리적 원인의 적혈구 용혈군의 제작 시 주사기의 흡입 및 유출의 강도가 일정하지 못하여 각각의 분주
용기별 용혈 정도의 표준화에 문제가 있는 점, 둘째 면역성 용 혈군을 상대적으로 구하기 쉽지 않아 그 수가 비교 대상군에 비해 적은 점과 면역성 용혈군의 확진의 어려움, 셋째 대조군 과 비교군의 나이와 성별이 유사하게 짝지어지지 못한 점, 넷 째, 통계적으로 유의한 지표임에도 면역성 원인으로 인한 적혈 구 용혈군에서 물리적인 원인의 적혈구 용혈군보다 높은 값을 보인 지표만 선정된 점, 다섯째, 온혈구검사 지표 중 반정량 값 으로 산출되는 지표는 제외된 점, 여섯째, 면역성 용혈군과 물 리적 요인의 용혈군은 알고리즘에 포함되지 않은 수치들에서 많은 차이가 있었던 점 등을 언급할 수 있다. 따라서 본 연구에 서 산출한 지표를 실제 환자 결과 자료에 적용한 후 축적된 자 료를 바탕으로 지속적인 검증과정을 거쳐 용혈감별 알고리즘 을 추후 개선할 필요가 있을 것이다. 새롭게 개발된 알고리즘 을 이용한다면 용혈로 인한 검사의 오류를 예방하고, 불필요한 재검사를 줄이며, 보다 효과적인 검사를 수행할 수 있는 모델 로 개선할 수 있을 것으로 판단된다.

결론적으로, 이번 연구는 기존 선행된 물리적 원인의 적혈구 용혈 구별 알고리즘을 $\mathrm{EDTA}$ 항응고제가 포함된 혈액 검체에 적용해 보았고, 온혈구검사 관련 지표인 $\mathrm{MPV}$, 적혈구 ghosts, $\mathrm{mHb}-\mathrm{cHb}, \mathrm{MCHC}-\mathrm{CHCM}$ 를 이용한 새로운 알고리즘은 물 리적인 원인의 적혈구 용혈을 찾아내는 데 유용할 것으로 판단 하였다. 이외에도 물리적 원인의 적혈구 용혈과 면역성 원인의 적혈구 용혈을 감별 시 온혈구검사 관련 지표인 $\mathrm{MCV}, \mathrm{RDW}$, $\mathrm{HDW}, \mathrm{PMN} \%$, neutrophil\%를 이용하여 조기에 면역성 적 혈구 용혈을 물리적인 원인의 적혈구 용혈과 감별하는 알고리 즘을 개발하였다. 앞으로 이 알고리즘의 검증 및 개선을 위해 보다 광범위의 잘 설계된 추가연구가 필요할 것으로 생각된다.

\section{감사의 글}

이 연구는 대한임상검사정도관리협회 2015년 학술연구비 지원에 의해 이루어진 것이다.

\section{REFERENCES}

1. Lippi G, Plebani M, Di Somma S, Cervellin G. Hemolyzed specimens: a major challenge for emergency departments and clinical laboratories. Crit Rev Clin Lab Sci 2011;48:143-53.

2. Lifshitz MS. Preanalysis. In: McPherson RA, Pincus MR, editors. Henry's clinical diagnosis and management by laboratory methods. 23th ed. St. Louis (MO): Elsevier, 


\section{Journal of LABORATORY MEDICINE and QUALITY ASSURANCE}

Jong-Han Lee et al • Differentiating Mechanical and Immune Hemolysis

2017:20-32.

3. Laposata M, Dighe A. "Pre-pre" and "post-post" analytical error: high-incidence patient safety hazards involving the clinical laboratory. Clin Chem Lab Med 2007;45:712-9.

4. Clinical Laboratory and Standards Institute. Hemolysis, icterus, and lipemia/turbidity indices as indicators of interference in clinical laboratory analysis: approved guideline. Wayne (PA): Clinical Laboratory and Standards Institute, 2012.

5. Shin DH, Kim J, Uh Y, Lee SI, Seo DM, Kim KS, et al. Development of an integrated reporting system for verifying hemolysis, icterus, and lipemia in clinical chemistry results. Ann Lab Med 2014;34:307-12.

6. Yoo G, Kim J, Uh Y, Yoon KR, Park SD, Yoon KJ. Scoring system for detecting spurious hemolysis in anticoagulated blood specimens. Ann Lab Med 2015;35:341-7.

7. Siemens Healthcare Diagnostics Inc. ADVIA 2120/2120i hematology systems operator's guide. Tarrytown (NY): Siemens Healthcare Diagnostics Inc., 2010.

8. Pincus MR, Bock JL, Rossi R, Cai D. Chemical basis for analyte assays and common interferences. In: McPherson
RA, Pincus MR, editors. Henry's clinical diagnosis and management by laboratory methods. 23th ed. St. Louis (MO): Elsevier, 2017:428-40.

9. Elghetany MT, Schexneider KI, Banki K. Erythrocytic disorders. In: McPherson RA, Pincus MR, editors. Henry's clinical diagnosis and management by laboratory methods. 23th ed. St. Louis (MO): Elsevier, 2017:559-605.

10. Laessig RH, Hassemer DJ, Paskey TA, Schwartz TH. The effects of 0.1 and 1.0 per cent erythrocytes and hemolysis on serum chemistry values. Am J Clin Pathol 1976;66:639-44.

11. Zandecki M, Genevieve F, Gerard J, Godon A. Spurious counts and spurious results on haematology analysers: a review. Part I: platelets. Int J Lab Hematol 2007;29:4-20.

12. Lippi G, Musa R, Avanzini P, Aloe R, Pipitone S, Sandei F. Influence of in vitro hemolysis on hematological testing on Advia 2120. Int J Lab Hematol 2012;34:179-84.

13. Noris P, Melazzini F, Balduini CL. New roles for mean platelet volume measurement in the clinical practice? Platelets 2016;27:607-12. 
항응고제가 첨가된 혈액 검체에서 생체 외와 생체 내 용혈의 감별 진단 알고리즘

\section{이종한 ${ }^{1}$ - 김윤정 ${ }^{2}$ 유길성 ${ }^{1}$ 김주원 ${ }^{1}$ - 윤갑준 ${ }^{1}$ 어 영 $^{1}$}

${ }^{1}$ 연세대학교 원주의과대학 진단검사의학교실, ${ }^{2}$ 연세대학교 의과대학 진단검사의학교실

배경: 용혈 검체는 여러 가지 임상검사결과에 다양한 간섭 영향을 주게 된다. 이번 연구에서는 기 존 물리적인 원인의 용혈을 판단하는 선행 용혈지표를 검증하고, 나아가 물리적인 원인의 적혈구 용혈과 면역성 원인의 적혈구 용혈을 감별해내는 진단 알고리즘을 온혈구 검사결과를 통하여 개발 하고자 하였다.

방법: 건강검진을 위해 내원한 63명의 정상대조군 EDTA (ethylenediamine tetraacetic acid) 혈액 잔 여 검체를 이용하여 이를 3개의 검체로 분주한 후 정상대조군과 2회와 5 회씩 일회용 주사기를 흡 입 유출하여 인위적으로 물리적인 용혈군을 만들었다. 또한 직접항글로불린검사를 포함한 다양한 검사결과를 토대로 면역성 적혈구 용혈군으로 의심되는 36명의 대상자를 선정하였다. 정상대조군 (A군), 2회 용혈군(B군), 5 회 용혈군(C군), 2회와 5 회용혈군을 합한 군(D군), 면역성 용혈군( $\mathrm{E}$ 군)을 선 정하여 각 군 간 통계적 유의성을 검증하였다.

결과: 물리적 용혈군을 선별하는 능력은 평균혈소판용적, 적혈구 ghosts, 측정혈색소치-계산혈색 소치, 평균적혈구헤모글로빈농도-적혈구혈색소농도평균의 용혈지표 점수의 합이 기존 보고된 평 균적혈구헤모글로빈농도, 적혈구 ghosts, 측정혈색소치-계산혈색소치, 평균적혈구헤모글로빈농 도-적혈구혈색소농도평균의 용혈지표 점수의 합과 동등한 수준이었다. 또한 평균적혈구용적, 적혈 구크기분포폭, 혈색소분포폭, 다형핵백혈구 \%, 중성구 \% 값을 이용한 새로운 지표는 물리적 원인의 용혈군과 면역성 원인의 용혈군을 감별해내는 능력이 우수하였다(경계치, 9; 민감도, $91.7 \%$; 특이 도, 92.9\%; 곡선하면적, 0.965 [95\% 신뢰구간, 0.924-0.988]).

결론: 새롭게 개발된 알고리즘은 적혈구 용혈을 검출하고 물리적인 원인의 용혈과 면역성 원인의 용혈을 감별해내는 효과적인 선별검사로 이용될 수 있다.

(J Lab Med Qual Assur 2017;39:132-140)

교신저자: 어 영

우)26426 강원도 원주시 일산로 20 , 연세대학교 원주의과대학 진단검사의학교실

Tel: 033)741-1592, Fax: 033)731-0506,E-mail: u931018@yonsei.ac.kr 